\title{
Extensive Recurrence of a Parotid Carcinoma After Primary Radiotherapy
}

\author{
Ö. Göktas* and T. Schrom
}

\author{
${ }^{I}$ ENT Department, Charité Campus Mitte, Charité Universitätsmedizin Berlin, Germany
}

\begin{abstract}
Background: Parotid gland malignancies are primarily treated by surgery. Particularly extensive tumor recurrences mostly require very large-scale and cosmetically unfavorable interventions. Unclear anatomic conditions often restrict the intraoperative orientation. This case report demonstrates the markedly improved quality of life achieved despite the complexity of the intervention.
\end{abstract}

Patient: A 62-year-old male patient presented to our emergency room with acute bleeding from a parotid tumor. The clinical examination revealed a $5 \mathrm{~cm}$ massively bleeding necrotic tumor crater colonized with fly maggots in the right preauricular region. The patient also had a complete peripheral facial palsy of House-Brackmann Grade VI. Primary irradiation had been performed for a parotid mucoepidermoid carcinoma one and a half years ago.

Clinical Course: First, the bleeding was stopped by embolizing the anterior auricular branch of the superficial temporal artery. Restaging yielded a tumor status of kT4 kN2b M0. The subsequent tumor resection included a hemimandibulectomy, a resection of the auricle with the auditory canal and middle ear, a mastoidectomy with microsurgical facial nerve reconstruction, and a modified radical neck dissection on the right side. We used a pectoralis major myocutaneous flap to close the defect after achieving tumor-free resection margins. The lagophthalmos was treated by pretarsal implantation of a platinum chain. Wound healing was uneventful. The histological examination showed the R0 resection of the previously diagnosed mucoepidermoid carcinoma. The patient was discharged in good general condition and is undergoing shortinterval follow-ups in our tumor dispensary. After the tumor resection and primary healing, the patient received an adhesive ear epithesis to improve the aesthetic results.

Conclusion: Even patients with tumor recurrence after primary radiation therapy can profit by extensive surgical treatment. The quality of life can thus be markedly improved even in a palliative situation. The option of complex interventions for extensive tumor recurrences should be integrated in an effective overall concept and discussed with the patients.

Keywords: Parotid carcinoma, tumor recurrence, facial nerve palsy of House-Brackmann, pectoralis major myocutaneous flap, quality of life.

\section{CASE DESCRIPTION}

\section{History}

A 62-year-old male patient presented with acute bleeding from a tumor in the right parotid gland. During the past few weeks, minor bleeding from the tumor region had occurred repeatedly but had always stopped. Primary irradiation had been performed for an inoperable mucoepidermoid carcinoma of the right parotid gland one and a half years ago.

\section{Findings and Diagnostics}

The ENT examination revealed an approximately $5 \mathrm{~cm}$ necrotic tumor crater in the right preauricular region that bled massively and was colonized with fly maggots. A right facial palsy of House-Brackmann Grade VI was also detected. The patient reported having had this since the initiation of radiation therapy one and a half years ago. After removing the maggots and inserting a Tabotamp gauze for temporary bleeding control (Fig. 1), complete hemostasis was achieved by embolizing the anterior auricular branch of the right superficial temporal artery. Restaging disclosed the ulcerated tumor in the right parotid gland without skull base infiltration (cervical CT, Fig. 2) with ipsilateral lymph node

*Address correspondence to this author at the ENT Department, Charité Campus Mitte, Universitätsmedizin Berlin, Chariteplatz 1, D-10117 Berlin, Germany; E-mail: oender.goektas@charite.de

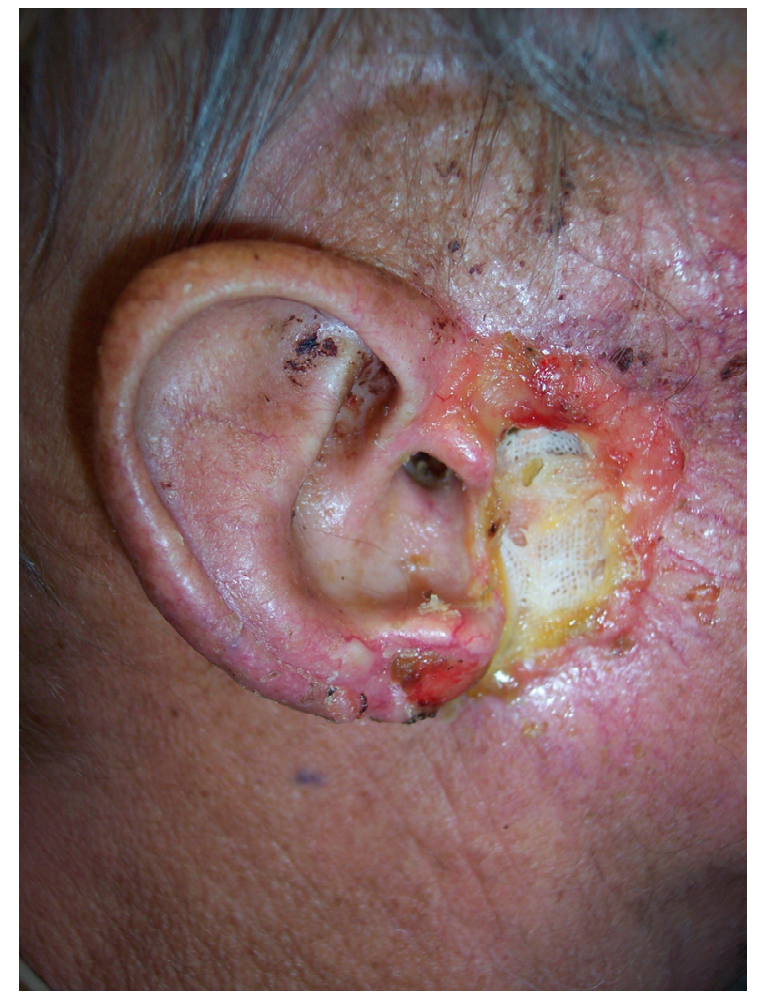

Fig. (1). Patient presented with tumor bleeding, Tabotamp gauze inserted in tumor crater. 


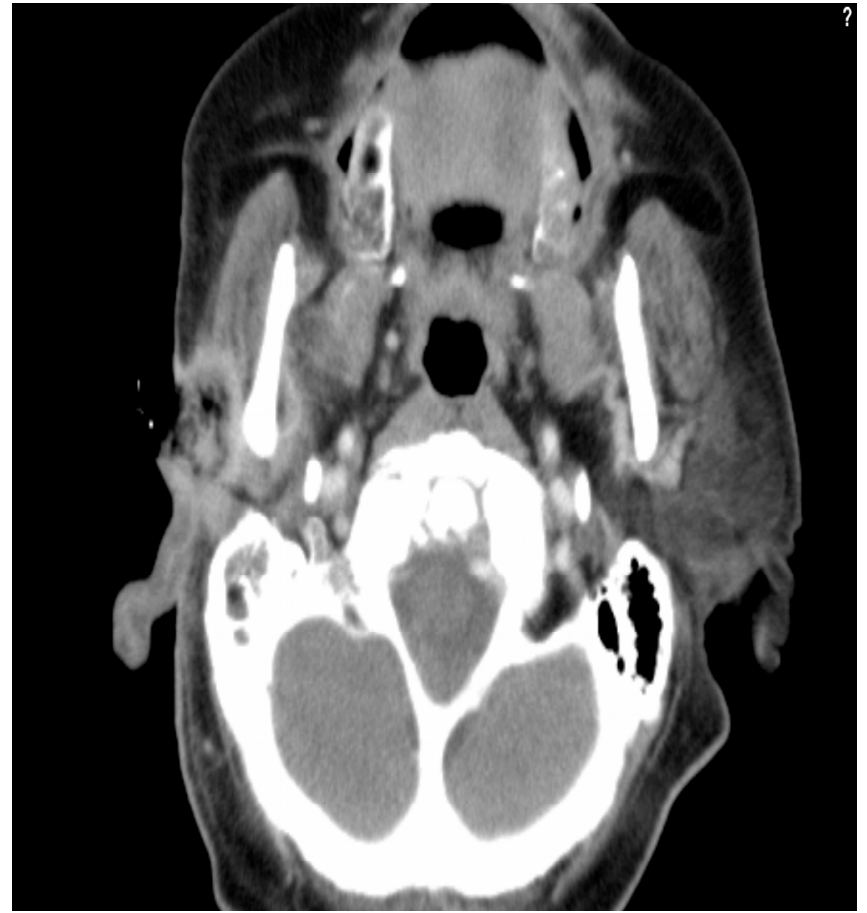

Fig. (2). Ulcerated tumor with infiltration of the masseter muscle in the right preauricular region (cervical CT).

metastases. No further tumor manifestations or distant metastases were detected. The tumor was classified as stage cT4 N2b M0.

\section{Therapy}

Repeat irradiation with curative intent was not possible on consultation with the radiotherapists. An alternative was chemotherapy with palliative intention. After the remaining option of an operative intervention had been discussed in detail with the patient, the decision was made in favor of a surgical procedure. We then performed a radical tumor resection with a hemimandibulectomy, a resection of the auricle, auditory canal and middle ear, a mastoidectomy and a modified radical neck dissection on the right side. The diversification technique according to Stennert [1] was employed for microsurgical facial nerve reconstruction, using the ansa cervicalis for the buccal branch and autonomic nerve transposition with the cervical plexus for the ocular branch. The defect was closed by a pectoralis major myocutaneous flap after tumor-free marginal resection (Fig. 3). The lagophthalmos was treated by pretarsal fixation of a platinum chain on the right side. Lower jaw reconstruction was not performed.

\section{Clinical Course}

Wound healing was uneventful (Fig. 4). The histological examination showed a complete R0 resection of the previously diagnosed mucoepidermoid carcinoma (Fig. 5). The patient was discharged in very good general condition and is undergoing short-interval follow-ups in our outpatient tumor consultation service. He had no complaints in terms of dizziness but a maximal conductive hearing loss due to complete occlusion of the auditory canal and middle ear. After tumor resection and primary healing, the patient received an adhesive ear epithesis to improve the aesthetic results (Fig. 6).

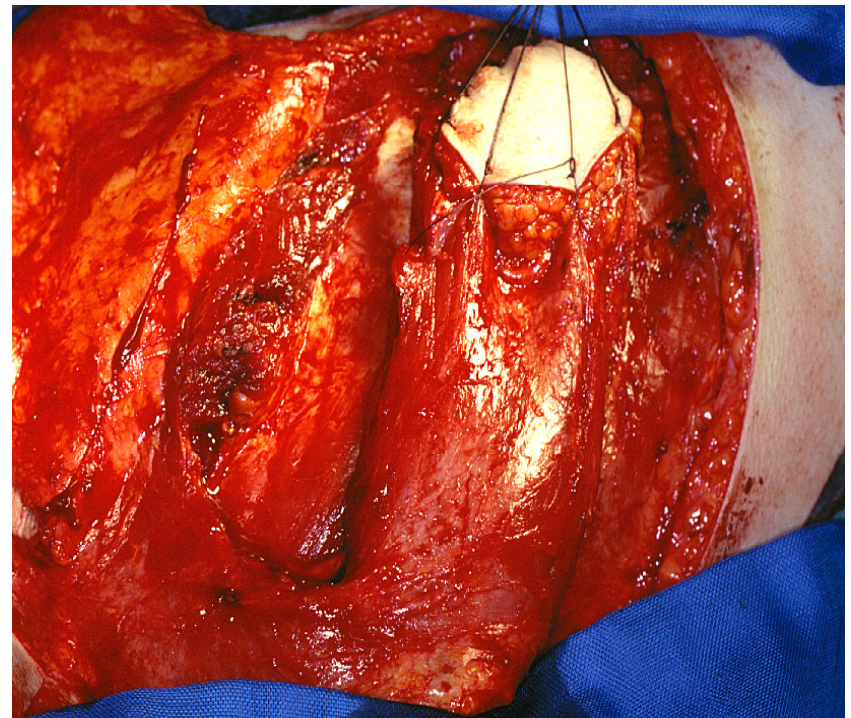

Fig. (3). Intraoperative view of the pectoralis major myocutaneous flap.

He has shown no signs of tumor recurrence over the 9 months that have elapsed thus far. He does not have lockjaw or mastication problems. If facial nerve palsy persists, complete eyelid closure can be achieved by using a platinum chain for lid loading.

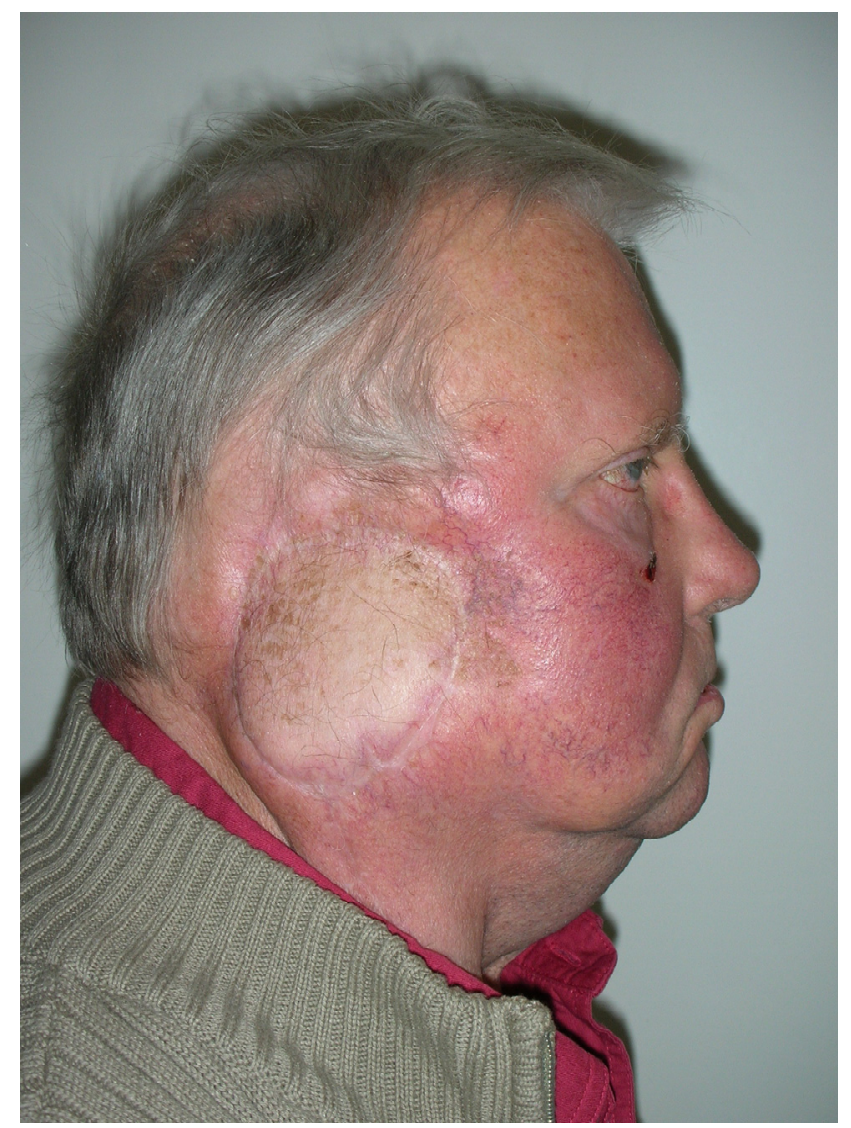

Fig. (4). Wound healing after radical tumorresection.

\section{ASSESSMENT AND DISCUSSION}

Together with adenoid cystic carcinomas, mucoepidermoid carcinomas are the most common malignant salivary 


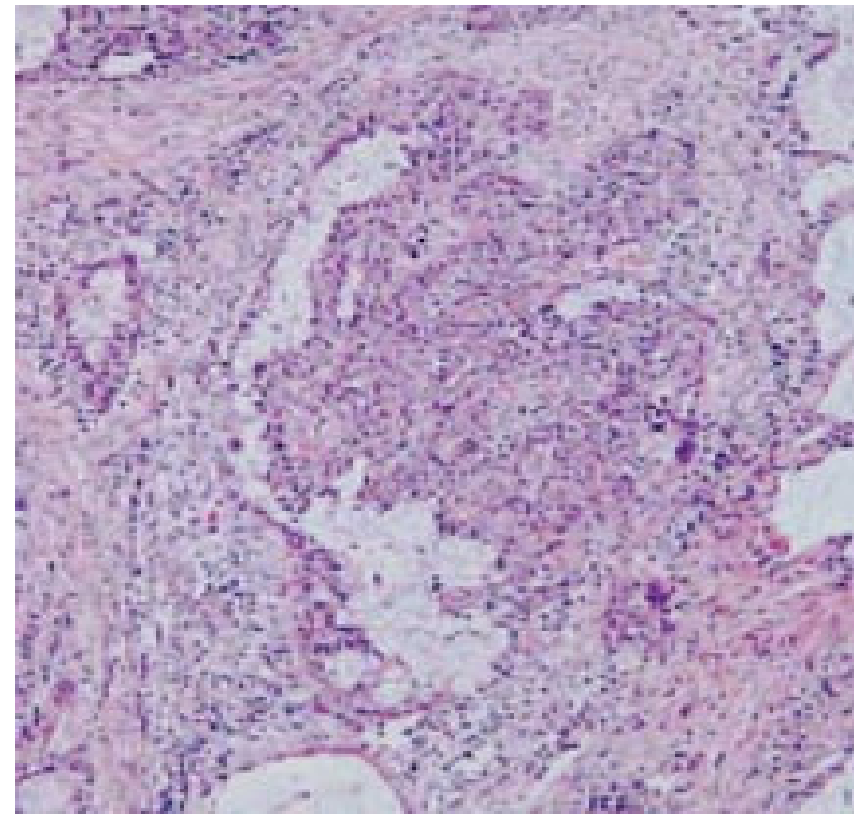

Fig. (5). histopathological view of the mucoepidermoid carcinoma: Solid and cystic components (HE x 100).

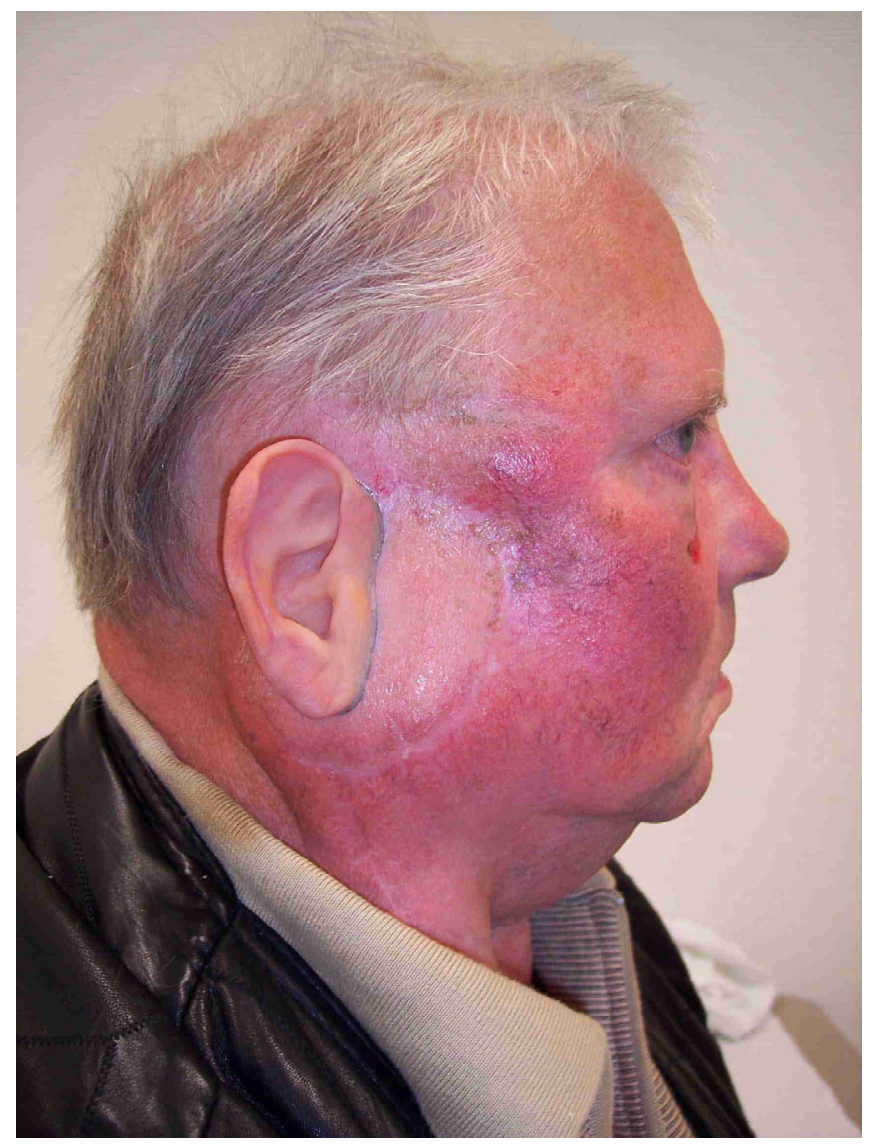

Fig. (6). Patient with ear epithesis.

gland tumors [2]. Both malignant growths can occur at any age $[3,4]$. The etiology [5] is unknown. Chromosome translocation with the creation of fusion genes has recently been discussed in the literature [6]. A t translocation is thought to be present in about $60 \%$ of the mucoepidermoid carcinomas $(11 ; 19)$. Moreover, there have been case examples of a mucoepidermoid carcinoma developing after radioiodine ther- apy for primary thyroid carcinoma [7]. Mucoepidermoid carcinoma manifests in the parotid gland in about 50\%. Histologically, this is a sharply demarcated tumor with both cystic and solid components. The neoplasms can be differentiated into low-grade types with predominantly cystic lesions, intermediate-grade types, and high-grade types with a predominantly solid growth pattern. According to the literature, this grading is prognostically relevant for mucoepidermoid carcinomas of the minor salivary glands and parotid glands [8-10]. Ipsilateral lymph node involvement is prognostically unfavorable [11-12]. High-grade mucoepidermoid carcinomas have a particularly poor prognosis with a recurrence rate of $25 \%$ and a 10 -year survival rate of less than $50 \%$ [13-15].

Extensive recurrences of previously irradiated malignant salivary gland tumors are a therapeutic challenge. Apart from repeat radiotherapy (possibly combined with chemotherapy) or palliative chemotherapy, complex surgical procedures may basically also be performed. Surgical resection with curative intent is difficult and often leads to considerable quality-of-life impairment and a marked increase of possible peri- and postoperative complications. Since our patient had already been irradiated one and a half years ago, our radiotherapists rejected the option of repeat irradiation. Even neutron irradiation, which some authors favor for inoperable tumors [16], was out of the question. After thoroughly informing the patient, we decided to perform a radical tumor resection including the external ear, auditory canal, mastoid and lower jaw. The defect was closed by a pectoralis major myocutaneous flap. The diversification technique described by Stennert [1] was used for microsurgical facial nerve reconstruction, and the paralytic lagophthalmos was treated by a platinum chain implant. In addition, an adhesive ear epithesis was fitted after primary healing. The patient refused the implantation of an epithesis anchor. The patient is having regular follow-ups and has been recurrence-free for 9 months. There has been no recovery of active facial nerve function up to now

\section{CONCLUSION FOR CLINICAL PRACTICE}

It is difficult to treat previously irradiated malignant salivary gland tumors. Apart from repeat irradiation or chemotherapy with palliative intent, there is the option of performing complex surgical procedures. The aim of surgery should be to resect the tumor as completely as possible and to enable a high postoperative quality of life. The possible interventions should be discussed in detail with the patients and integrated in an effective overall concept in order to minimize peri- and postoperative complications.

\section{REFERENCES}

[1] Stennert E, Jungehülsing M. Chirurgie der Glandula parotis einschließlich rekonstruktiver Fazialis-Chirurgie: Standard und Qualitätssicherung. Laryngo-Rhino-Otologie 2001; 80: 156-197.

[2] Ellis GL, Auclair PL, Gnepp DR, Goode RK. Other malignant epithelial neoplasms. In: Ellis GL, Auclair PL, Gnepp DR (eds.). Surgical pathology of the salivary glands. Philadelphia, London, Toronto, Montreal, Sydney, Tokyo: Saunders, 1991: 445-488.

[3] Loy TS, McLaughlin R, Odom LF, Dehner LP. Mucoepidermoid carcinoma of the parotid as a second malignant neoplasm in children. Cancer 1989; 64: 2174-2177.

[4] Seifert G, Miehlke A, Haubrich J, Chilla R. Diseases of the salivary glands. Pathology-diagnosis-treatment-facial nerve surgery. Stuttgart, New York: Thieme, 1986. 
[5] Donath K, Ußmüller J. Ätiopathogenese und Histopathologie der Speicheldrüsenerkrankungen. Laryngo-Rhino-Otologie 2001; 80: $1-25$.

[6] Röser R, Jäkel KT, Bullerdiek J, Löning L. Bedeutung molekularzytogenetischer Befunde bei Speicheldrüsentumoren am Beispiel des Mukoepidermoidkarzinoms. Der Pathologe 2005; 26 (5): 359366.

[7] Henze M, Hittel JP. Mukoepidermoid-Karzinom der Speicheldrüsen nach hochdosierter Radiojodtherapie. Laryngo-Rhino-Otologie 2001; 80: 253-256.

[8] Auclair PL, Goode RK, Ellis GL. Mucoepidermoid carcinoma of intraoral salivary glands: evaluation and application of grading criteria in 143 cases. Cancer 1992; 69: 2021-2030.

[9] Goode RK, Auclair PL, Ellis GL. Mucoepidermoid carcinoma of the major salivary glands : clinical and histopathologic analysis of 234 cases with evaluation of grading criteria. Cancer 1998; 82: 1217-1224.

[10] Löning T, Jäkel KT. Spiecheldrüsentumoren-Tumortypisierung und Grading. Der Pathologe 2004; 25: 38-45.
[11] Ball AB, Rajagopal G, Thomas JM. Malignant epithelial parotid tumours. Ann R Coll Surg Engl 1990; 72: 247-249.

[12] Calearo C, Pastore A, Storchi OF, Polli G. Parotid gland carcinoma: analysis of prognostic factors. Ann Otol Rhinol Laryngol 1998; 107: 969-973.

[13] Chomette G, Auriol M, Tereau Y, Vaillant JM. Mucoepidermoid tumors of minory salivary glands. Clinical and pathologic correlations. Histoenzymologic and ultrastructural studies. Ann Pathol 1982; 2: 29-40.

[14] Spiro RH, Armstrong J, Harrison L, et al. Carcinoma of major salivary glands: major trends. Arch Otolaryngol Head Neck Surg 1989; 115: 316-321.

[15] Plambeck K, Friedrich RE, Schmelzle R. Mucoepidermoid carcinoma of the salivary gland origin: classification, clinical-pathological correlation, treatment results and long-term follow-up in 55 patients. J Craniomaxillofac Surg 1996; 24: 133-139.

[16] Chilla R. Diagnostik und Therapie der Speicheldrüsentumoren: HNO Teil I+II: 627-633, 681-694. 